\title{
Sulmasy et al.: Physician-Assisted Suicide: Against Medical Neutrality
}

\author{
Kristel Clayville, $P h D^{7}$ and Pringl Miller, MD, FACS ${ }^{2}$
}

'Zygon Center for Religion \& Science, Lutheran School of Theology at Chicago, Chicago, IL, USA; '2Departments of Medicine \& Surgery, Section of Palliative Medicine, Rush University Medical Center, Chicago, IL, USA.

$\mathrm{J}$ Gen Intern Med 34(8):1371

DOI: $10.1007 / \mathrm{s} 11606-019-05020-8$

(c) Society of General Internal Medicine 2019

$\mathrm{S}$ ulmasy et al. oppose medical aid in dying (MAID) on the grounds there is a misinterpretation of respect for autonomy. In doing so, they argue for the radical autonomy of physicians, who are described as isolated clinicians with merely medical knowledge of their patients. This ignores the availability of interdisciplinary teams (IDT) caring for terminally ill patients that provide perspectives beyond the physician's medical knowledge.

They worry that the physician knows very little about their patients' lives. They point to family dynamics as an example of what is beyond the "ken and expertise of the physician." And yet, there are palliative medicine specialists trained to recognize and address psychological distress, reactions to illness, stress, coping strategies, and anticipatory grief. ${ }^{2}$ Moreover, hospice and palliative care interdisciplinary teams include physicians, nurses, social workers, and chaplains who have overlapping professional competencies in emotional distress, family systems, existential crises, and interpreting interpersonal relationships.

"All MAID statutes require that both the attending and consulting physician inform the patient about end-of-life options, including hospice and palliative care." According to the 2017 Joint Commission on Health Care MAID interim report, up to $89 \%$ of MAID users were enrolled in hospice and had access to palliative care. $^{3}$ Given that the IDT approach addresses some of

\footnotetext{
${ }^{1}$ Sulmasy et al. Physician-Assisted Suicide: Why Neutrality by Organized Medicine Is Neither Neutral Neutral Nor Appropriate. Journal of General Internal Medicine. 2018. DOI: https://doi.org/10.1007/s11606-018-4424-8

2 National Consensus Project for Quality Palliative Care. Clinical Practice Guidelines for Quality Patient Care. 3rd Edition. 2013. ISBN \# 1-9346654 35-3. www.nationalconsensusproject.org

3 Medical Aid-in-Dying (MAID) Interim Report Joint Commission on Health Care. August 22, 2017. Michele Chesser, PhD, Executive Director. http://jchc.virginia.gov/4.\%20Medical\%20Aid-in-Dying\%20Study.2017. FINAL\%20(1).pdf
}

No prior presentations, publications, or co-publications

Published online May 7, 2019 the authors' unease with MAID, we must ask why the physician is presented as an isolated clinician in this manuscript. Pitting the physician against the patient rather than as equal parts of an intersecting collaborative system detracts from a shared decision-making process. The patient and physician become autonomous agents trying to exert their wills on each other within a traditionally skewed power dynamic that does not always value patient centered care. In this context, the physician's sense of morality enters into the discussion and can eclipse the patient's sense of morality. For these authors, the conflict is resolved by reinforcing a patient's intrinsic value, optimizing symptom management, and supporting the refusal of unwanted intervention. If the physician can counsel about one's intrinsic value, then the physician has the competency to counsel about other subjective issues as well.

If a terminally ill patient with decision-making capacity chooses an earlier death over a longer life of suffering, intentionally prolonging suffering by erring on the side of life is contradictory to accepted clinical ethical principles and patient concordant care. For the $0.2 \%$ of terminally ill patients in the most recognized jurisdiction who end their lives utilizing MAID, neutrality represents erring on the side of quality over quantity of life.

Corresponding Author: Pringl Miller, MD, FACS; Departments of Medicine \& Surgery, Section of Palliative Medicine, Rush University Medical Center, Kellogg Building - Suite 1126, 1717 West Congress Parkway, Chicago, IL 60612, USA (e-mail: pringl_miller@rush.edu).

\section{Compliance with Ethical Standards:}

Conflict of Interest: The authors declare that they do not have a conflict of interest.

Publisher's Note Springer Nature remains neutral with regard to jurisdictional claims in published maps and institutional affiliations.

\footnotetext{
${ }^{4}$ The National Academies Press. Physician-Assisted Death: Scanning the Landscape: Proceedings of a Workshop. DOI https://doi.org/10.17226/ 25131. http://nap.edu/2513131
} 